\title{
Enhancing University Research Through Innovations in Graduate Education
}

\author{
Sarah C. Larsen, Associate Dean, Graduate College \\ Professor, Department of Chemistry \\ University of Iowa
}

G raduate education plays a critical role in the research infrastructure at research universities in the United States. The research experience is central to the doctoral degree and is closely connected to the university research enterprise as well as faculty productivity, particularly in Science, Technology, Engineering and Mathematics (STEM) disciplines. Similar to higher education considered broadly, graduate education faces many challenges including financial support for graduate students, effective diversity and inclusion efforts, and career transparency and preparation. In this paper, innovations in graduate education are presented as ways to meet these challenges.

\section{Introduction}

Graduate education plays a key role in university research. Specifically, graduate students are a critical component of the human capital supporting university research and innovation. In the recent publication, Public Research Universities: Why They Matter, published by the American Academy of Arts and Sciences in 2016, the public research university (PRU) is described as integral to the nation's core research in science, medicine, engineering and technology.[1] At PRUs, research is accomplished through the combined research efforts of faculty, graduate students, postdoctoral associates, undergraduate students, and research staff. From the graduate education perspective, PRUs award $65 \%$ of all masters' degrees and $68 \%$ of all research doctoral degrees worldwide.

The central role of graduate education to research was similarly articulated in The Path Forward: The Future of Graduate Education in the United States published by the Council of Graduate Schools and the Educational Testing Service in 2010. In this report, it was stated that: "The global competitiveness of the US and capacity for innovation hinges fundamentally on a strong system of graduate education." [2] The Path Forward report also projected that between 2008 and 2018, 2.5 million additional professional jobs will require graduate degrees.[2] These perspectives attest to the integral role of graduate education to innovation, to university research and to the significant role of the PRU.

However, graduate education is not immune to the challenges faced by all of higher education. The PhD Completion Project data indicated that doctoral completion rates and time to degree varied across fields of study with engineering having a 10-year doctoral completion rate of $64 \%$ compared to the humanities which had a 10 year completion rate of $49 \%$.[3] Overall, less than $25 \%$ of doctoral students completed degrees within five 
years and approximately 57\% completed degrees within 10 years. Financial support topped the list of critical elements contributing to doctoral completion with mentoring/advising and family support also being cited as important. In Section 2 , several different aspects of financial support for graduate students will be examined.

The experiences and success of underrepresented minority (URM) students in doctoral education is another topic of discussion. The data collected in the Survey of Earned Doctorates: 2014 indicates an overall upward trend in the number of doctorate degree recipients for Black/African American students and Hispanic/Latino students over the past 20 years.[4] Similar gains have not been observed for American Indian or Alaskan Native students. While the overall upward trend is encouraging, there are concerns about completion and about climate and inclusiveness. Diversity and inclusion in graduate education will be considered in more depth in Section 3.

Another aspect of doctoral graduate education that has been widely discussed is the misconception that the majority of doctoral students pursue tenure track academic careers. As research universities, such as PRUs, have faced intense budgetary crises, instructional needs are increasingly being met with nontenured and adjunct faculty. As a result, the availability of tenure track academic positions has not kept pace with the number of students earning doctorates. Increasingly, newly minted doctorates must find careers outside of traditional academic positions. About one half of new doctorates begin careers in business, government and nonprofit organizations with variations observed by field of study. [5] Employers have noted that doctoral graduates are innovative and talented researchers but lack some of the "transferrable" or "soft" skills needed to be successful in a range of different careers. Employers suggest universities create stronger connections between graduate school curricula and workforce/employer needs.[5]

In response, graduate colleges have extended their mission to serve graduate students by developing more robust professional development offerings at the institutional and program level with the goal of better preparing students for academic and nonacademic careers. These efforts aim to facilitate the development of students' nontechnical skills in preparation for a broader range of career outcomes. The issue of career transparency and professional development will be explored in section 4 .

\section{Financial Support for Graduate Education}

In a recent study of $\mathrm{PhD}$ completion and attrition by the Council of Graduate Schools, financial support was deemed the most significant factor impacting doctoral completion.[3] Financial support models have been explored in several recent studies that have cataloged various modes (research or teaching assistantship) and sources of funding. The National Science Foundation cataloged the primary sources of funding for graduate students overall and by discipline for the time period 2004-2014.[4] The results of the study indicated that research and teaching assistantships and fellowships account for the largest percentages of 




Figure 1. Primary source of financial support for doctoral recipients. Reproduced from reference 4.

support since 2010 (Figure 1). The percentage of students funded with their own resources has declined over this time period.

This report also considered support by field of study. Disciplinary trends emerged from the data as shown in Figure 2. Research assistantships account for the largest single source of support in the physical sciences and engineering while teaching assistantships are the largest source of support for the humanities disciplines. In contrast, doctoral students in education fields tend to rely heavily on their own financial resources. This variation across fields indicates that the funding challenges vary amongst the different disciplines and therefore, a multifaceted approach will be needed to address this issue.

In a recent study, the analysis was extended to examine federal funding expenditures by personnel categories which showed trends in how federal dollars were distributed across faculty, graduate students, undergraduate students, postdoctoral associates and staff. Weinberg and coworkers examined research expenditures as part of the UMETRICS
Primary Source of Financial Support by field of study, 2014

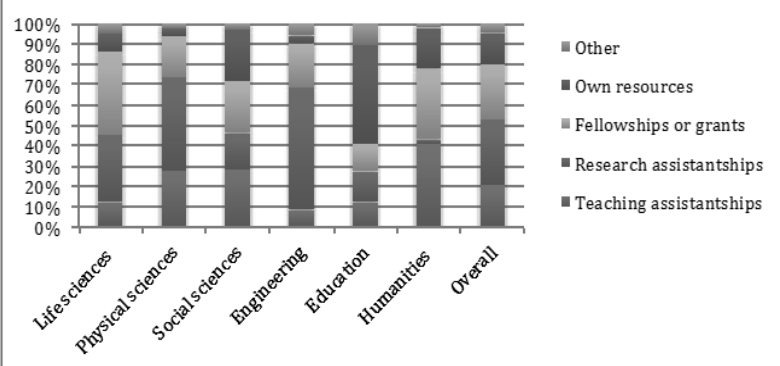

Figure 2. Primary source of financial support by field of study for doctoral recipients. Data obtained from reference 4 .

initiative and found that overall approximately one third of the personnel supported were graduate or undergraduate researchers.[6] Approximately 10\% were postdoctoral associates. The composition of the workforce varied according to funding source. Further, this study suggested that any changes in federal funding policies have the potential to have large impacts on graduate education and this impact varies by field of study. There are ongoing discussions in different STEM fields about the best model for graduate student support and whether this should be primarily through fellowships awarded to students or through research grants to faculty Principal Investigators. In the report, Advancing Graduate Education in the Chemical Sciences by the Society (ACS), the recommendation reached was that the financial support for graduate students in the chemical sciences is weighted too heavily toward individual research grants.[7] The report suggested that this can create a potential conflict of interest between the productivity of the Principal Investigator (usually a faculty member) and the educa- 
tional best interests of the graduate student. The report suggests that financial support provided directly to graduate students would result in a better balance between research training and career preparation of graduate students.

In The Path Forward, several recommendations for financial support for graduate education were discussed.[2] These recommendations included advocacy for increased federal funding of research through research grants, increased fellowships, including fellowships to broaden participation, and funding for internships and international experiences. Business/university partnerships were proposed for funding graduate students.

Universities should engage in dialogue with various constituencies including private donors, federal funding agencies and industrial partners to provide the financial resources necessary to support graduate students across the different disciplinary areas. The ultimate goal is to provide all incoming doctoral students with five to six-year funding packages that may include combinations of research, teaching assistantships and fellowships. The rationale is that stable funding packages will allow doctoral graduate students to focus on their research earlier in their careers by alleviating financial stressors. Additionally, varying the sources of financial support across a graduate student's career will ensure that graduate students' preparation is well-rounded and comprehensive. They have the opportunity to train in the lab, to teach, and to focus on their own research unfettered by the demands of an in-service position.

\section{Diversity and Inclusion}

Diversity and inclusion are critical to graduate education and central to the achievement of excellence in research universities. One goal of diversifying the student body is that this diversity will be reflected in the future workforce and will lead to innovation and long-term economic growth. Inclusion is central to the success of graduate programs because diverse learning environments improve student outcomes.[8] The link between diversity and excellence, particularly in scientific fields, is rooted in the belief that solving complex problems requires teamwork and is facilitated by diverse perspectives.[9]

Participation in doctoral education by U.S. students or permanent residents who are members of underrepresented minority (URM) populations has increased over the last 20 years. For example, the numbers of doctorates earned by Hispanic or Latino students has doubled from 1994 to 2014 while the numbers of doctorates earned by Black or African American students has increased by $70 \%$ as shown in Figure 3. Despite this progress, Black/African American, and Hispanic /Latino students are still underrepresented in graduate education relative to the representation of these groups in the U.S. population. [2]

Efforts are in place to increase the participation of URM students in graduate education. Many of these efforts have focused on recruitment and admissions processes. The Council of Graduate Schools recently released a report on $\mathrm{Ho}$ listic Review in Graduate Admissions.[8]

Holistic review refers to the consideration of a broad range of credentials beyond quantitative measures such as 


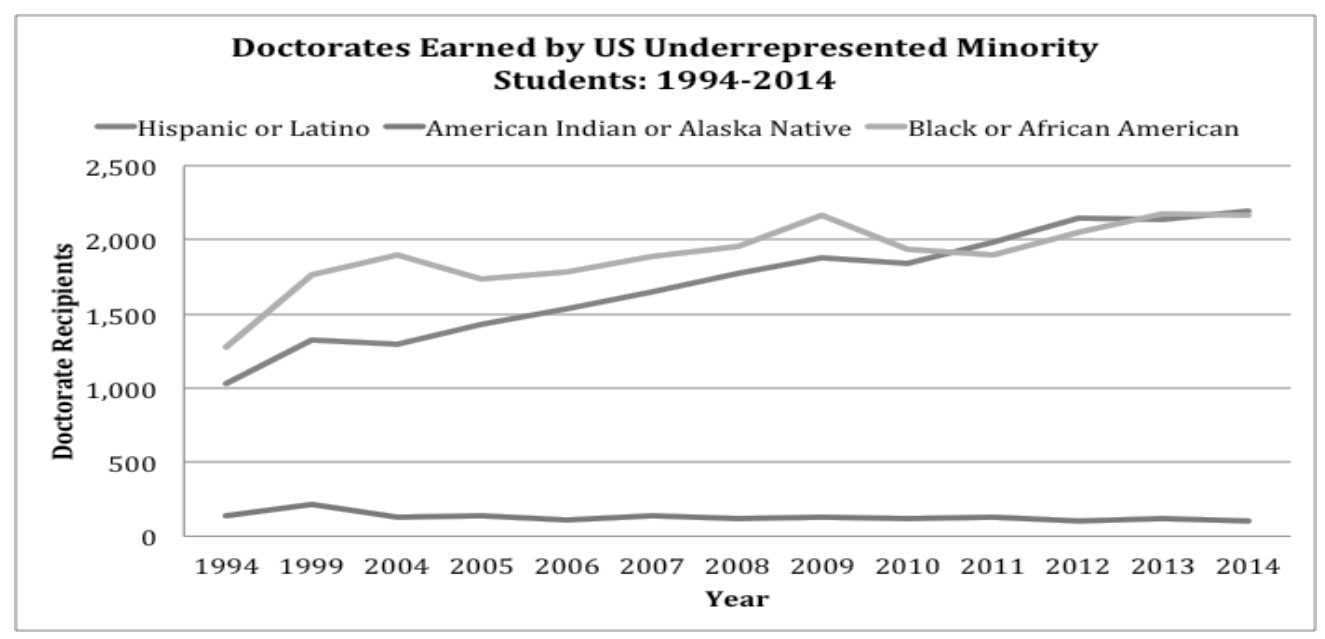

Figure 3. Doctorates earned by URM students. (Data obtained from reference 4.)

grades and test scores to evaluate admissions candidates. Holistic review is generally associated with improving diversity in higher education broadly. Holistic review involves consideration of noncognitive or personal traits such as creativity, leadership, or persistence in addition to more traditional quantitative measures. One challenge to implementing holistic review in graduate admissions is that graduate admissions tends to be decentralized and labor intensive. The CGS report[8] includes a list of promising practices:

- Articulated commitment to diversity at the institution

- Data analysis to identify gender and/or race-based patterns in admissions

- Faculty development related to admissions (e.g. appropriate use of GRE scores, preferred order for file review)

- Clear communication and coordination between recruitment and admissions

- Use of rubrics for applicant evaluation which include noncognitive measures. To further develop holistic review as an effective strategy for graduate ad- missions, compelling data connecting admissions criteria and graduate student success is needed.

In addition to recruiting and admissions considerations related to diversity, there is a need for increased retention and completion efforts to support the success of URM graduate students. For example, data indicates that URM doctoral students in STEM fields have lower completion rates and higher attrition rates relative to all STEM doctoral students.[3] The PhD Completion Project found that for U.S citizens and permanent residents, the tenyear doctoral completion rates were $55 \%$ for White students, $51 \%$ for Hispanic/Latino students and $47 \%$ for Black/African American students.[3] The Doctoral Initiative on Minority Attrition and Completion (DIMAC) focused on URM doctoral students in STEM disciplines.[10] The findings indicated that the seven year completion rates for Black/African American students and Hispanic/Latino students were below $50 \%$. Recommendations from the DIMAC project for increasing URM doctoral completion and retention included[10]: 
- Early and frequent interventions

- Enhanced academic support

- Monitoring and evaluating interventions

- Cultivating a climate of diversity and inclusion

Creating an environment where URM graduate students can thrive depends on increased institutional initiatives aimed at improving campus climate around inclusion and facilitating graduate student success with attention to the specific experiences of URM students.

\section{Career Transparency and Prepa- ration}

With more than half of all doctoral graduates finding employment in nonacademic careers, there is a need for earlier exposure to multiple career pathways in graduate education. $[2,5,11]$ The broad overview of doctoral career pathways includes: 1) faculty positions at research or teaching colleges and universities 2) nonacademic research careers (industry, government, startup company); and 3) nonresearch careers (consulting, science writing and policy, patent law).

In a recent study, Zolas and coworkers combined data from UMETRICS on graduate students supported by funded research and from the U.S. Census $\mathrm{Bu}-$ reau.[12] Analysis of the data showed that for doctoral students receiving their doctorates from 2009-2011, approximately $40 \%$ obtained industrial jobs. Interestingly, geographical clustering in employment was also observed near the university where the student trained.

Beyond exposure, it is generally agreed that graduate students should also be provided with enhanced professional development opportunities that will complement traditional research training and enhance employability. This call is echoed by the recent report The Path Forward, which suggested that to be competitive globally, U.S. universities should offer professional development programs for graduate students so that they can develop career and "soft" or transferrable skills.[2] The ACS report, Advancing Graduate Education in the Chemical Sciences, concluded that "current educational opportunities for graduate students, viewed on balance as a system, do not provide sufficient preparation for their careers after graduate school."[7] Further, the report called for university and government leaders to advance opportunities for graduate students to develop critical professional skills.[7]

Nationally, graduate students report increased interest in nonacademic careers and acquiring the skills that would support this pursuit.[13, 14] Despite this interest, many universities do not have a systematic way to integrate professional development activities into the lives of graduate students. Unlike undergraduate offerings, graduate student professional development often lacks a clear roadmap or campus infrastructure to support it.[15] Without career education or tools to reflect on career decisions, a large number of graduate students find themselves in a holding pattern as postdoctoral researchers, where despite decreased interest in a faculty career, they follow the trajectory that appears most familiar.

This issue has been acute in the biomedical sciences where, since 2011, fewer than $20 \%$ of the PhD's have been moving into tenure track academic positions 
within 5-6 years of receiving the PhD.[16] Fuhrman suggests that this branching career pipeline should be supported by changes in graduate training and mentoring to include professional and career development.[16] Through the Broadening Experience in Scientific Training (BEST) grant program that focuses on preparation for careers outside of the traditional academic environment, the National Institutes of Health (NIH) is specifically addressing the issues of the training needs of the biomedical $\mathrm{PhD}$ workforce.

At the University of Iowa (UI), approximately $28 \%$ of graduate student respondents to our exit survey reported that they did not receive any advice about nonacademic career options from their primary research advisor. This data represents the average over 3 semesters of the exit survey (Spring 2014-15 and Fall 2014). In an effort to begin to address this gap in information, the UI Graduate College developed the "Open Doors Career Education" series for graduate students. Featuring an annual careers conference, networking resources and video podcasts, the Open Doors series is designed to provide students with both face-to-face and virtual opportunities to discover new career paths. The Open Doors conference is an annual event serving over 100 graduate students and featuring UI alumni and other PhDs in non-academic careers. In video podcasts, graduate students can explore careers ranging from teaching at a liberal arts college to doing research in the private sector. Students can join in the conversation live or can view the video podcasts on the website. In addition to the Open Doors series, the UI Graduate College has organized professionalization across campus based on eight key academic and professional competencies including: 1) Research and Publication; 2) Teaching; 3) Communication; 4) Careers; 5) Diversity; 6) Funding; 7) Leadership; and 8) Wellness. The professional and career development offerings in each of these areas are planned in coordination with UI campus partners, such as the Center for Teaching, the Libraries, and the Department of Rhetoric. The Graduate College serves as the central hub for event promotion.

\section{Conclusions}

Graduate education is central to the mission of research universities in the U.S. Challenges in graduate education include financial support, diversity and inclusion, career training, and transparency. Recent initiatives across research universities focus on providing graduate students with stable and varied financial support, improving the climate for diversity and inclusion and providing enhanced career services and transparency. Through these innovations in graduate education, the research mission of the university will be strengthened.

\section{Acknowledgements}

I would like to acknowledge my University of Iowa Graduate College colleagues for valuable discussions, in particular Associate Provost and Graduate College Dean John C. Keller and Assistant Deans Heidi Arbisi-Kelm and Jennifer Teitle. 


\section{References}

1. Public Research Universities: Why They Matter. American Academy of Arts and Sciences. 2016: Cambridge, MA.

2. The Path Forward: The Future of Graduate Education in the United States. Report from the Commission on the Future of Graduate Education in the United States. Council of Graduate Schools and Educational Testing Service. , 2010.

3. Sowell, R.S., T. Zhang, N. Bell, and K. Redd, Ph.D. Completion and Attrition: Analysis of Baseline Demographic Data from the ph.D. Completion Project. 2008, Council of Graduate Schools: Washington, DC.

4. National Science Foundation, National Center for Science and Engineering Statistics. 2015. Doctorate Recipients from U.S. Universities: 2014. Special Report NSF 16-300. Arlington, VA. Available at http://www. nsf.gov/ statistics/2016/nsf16300/. 2015.

5. Pathways Through Graduate School and Into Careers. Council of Graduate Schools and Educational Testing Service, 2012.

6. Weinberg, B.A., J. Owen-Smith, R.F. Rosen, L. Schwarz, B.M. Allen, R.E. Weiss, and J. Lane, Science Funding and Short-Term Economic Activity. Science, 2014. 344(6179): p. 41-43.

7. Advancing Graduate Education in the Chemical Sciences. American Chemical Society, 2012.

8. Kent, J.D. and M. McCarthy, Holistic Review in Graduate Admissions: A Report from the Council of Graduate Schools. 2016, Council of Graduate Schools: Washington D.C.
9. Page, S.E., The Difference. 2007, Princeton, New Jersey: Princeton University Press.

10. Sowell, R., J. Allum, and O. H., Doctoral Initiative on Minority Attrition and Completion. 2015, Council of Graduate Schools: Washington, DC.

11. Revisiting the STEM Workforce (A Companion to Science and Engineering Indicators 2014), National Science Foundation. 2015, National Science Board.

12. Zolas, N., N. Goldschlag, R. Jarmin, P. Stephan, J. Owen-Smith, R.F. Rosen, B.M. Allen, B.A. Weinberg, and J.I. Lane, Wrapping it up in a person: Examining employment and earnings outcomes for Ph.D. recipients. Science, 2015. 350(6266): p. 1367-1371.

13. Turk-Bicakci, L., A. Berger, and C. Haxton, The Nonacademic Careers of STEM PhD Holders. American Institutes for Research, 2014.

14. Wheadon, M. and N. Duval-Coueti, Student Perspectives on Developing More Relevant PhD Programs in STEM disciplines through Professional Skills Training, 21st American Society for Engineering Annual Conference and Exposition. 2014. p. 10495.

15. Patel, V., New Job on Campus: Expanding PhD Career Options. Chronicle of Higher Education, January 12, 2015.

16. Fuhrmann, C.N., D.G. Halme, P.S. O'Sullivan, and B. Lindstaedt, Improving Graduate Education to Support a Branching Career Pipeline: Recommendations Based on a Survey of Doctoral Students in the Basic Biomedical Sciences. CBE-Life Sciences Education, 2011. 10(3): p. 239-249. 